\title{
QUALITY PAPER \\ Examining country development indicators and e-waste under the moderating effect of country development levels and e-waste policy
}

\author{
Prateek Kalia
}

Department of Corporate Economy, Faculty of Economics and Administration, Masaryk University, Brno, Czech Republic

Adil Zia

Department of Marketing, College of Business Administration, Al Baha University, Al Baha, Saudi Arabia, and

Dušan Mladenović

Department of Corporate Economy, Faculty of Economics and Administration, Masaryk University, Brno, Czech Republic

\begin{abstract}
Purpose - The purpose of this paper is to investigate if country development indicators, i.e. gross domestic product per capita (GDPPC), literacy rate, internet penetration and urban population, influence the generation of e-waste on a global level. The moderation effect due to differences between countries in terms of absence or presence of e-waste policy and level of development is also checked.

Design/methodology/approach - This is an archival study that builds upon data from United Nations (UN), World Bank and Global E-waste Statistics Partnership. The authors did a path analysis comprising mediation and multigroup analyses to decipher the proposed rese arch model containing data from 172 countries.

Findings - The results indicate that GDPPC, literacy rate, internet penetration and urban population do not directly influence the generation of e-waste. However, higher internet penetration in developing countries leads to higher e-waste, while higher literacy rates in developed countries suppress e-waste generation. When it comes to e-waste policy, a higher urban population without a regulatory legal framework boosts higher e-waste. The authors observed that higher internet penetration leads to higher e-waste in the presence of e-waste policy as well. Originality/value - This is the first study to include economic well-being indicators in elaborating e-waste generation, on a global scale. No previous study has observed differences between countries nested in e-waste policy and level of development.
\end{abstract}

Keywords GDP, Literacy rate, Internet penetration, Urban population, Country, E-waste policy

Paper type Research paper

(C) Prateek Kalia, Adil Zia and Dušan Mladenović. Published by Emerald Publishing Limited. This article is published under the Creative Commons Attribution (CC BY 4.0) licence. Anyone may reproduce, distribute, translate and create derivative works of this article (for both commercial and non-commercial purposes), subject to full attribution to the original publication and authors. The full terms of this licence

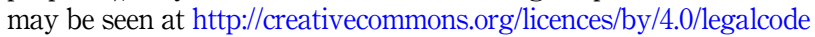

The authors acknowledge the APC voucher provided by Masaryk University, Brno, Czech Republic for open access publishing.

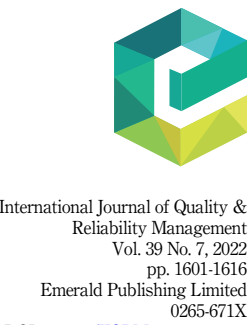

DOI 10.1108/JORM 0265-671X 
IJQRM

39,7

\section{Introduction}

Starting from 2010, the generation of electronic waste or e-waste has been on the rise - reaching 53 million metric tons in 2019 (Van Yken et al., 2021). Only slightly more than 17\% of this figure was properly collected and recycled. Given the fast-developing technological environment, changing consumer behavior, population growth, shorter lifespans of products and overall dynamic on the market, e-waste is recognized as the fastest growing waste stream nowadays (Favot and Grassetti, 2017; Liu et al., 2021). E-waste includes a broad category of electronic products (e.g. television, monitors, LCD equipment, DVD players, mobile devices, refrigerators, air conditioner units, etc.) (Borthakur, 2020; Jayaraman et al., 2019). A major motivation for ewaste management comes from the fact that e-waste contains great quantities of precious and valuable materials (Zhang et al., 2019). Every electronic product has a somewhat limited lifespan after which it should be discarded properly (Andersson et al., 2019). This presents a growing problem, given that plenty of countries lack proper regulation, overall awareness and institutions to impose proper disposal, recycling and reuse of e-waste (Patil and Ramakrishna, 2020; Ravindra and Mor, 2019; Shittu et al.,2021;Zhang et al., 2019). Even more problematic is the direct threat to the ecosystem and human health in general (Jayaraman et al., 2019).

The literature reports an increasing number of scientific outputs that investigated various aspects of the e-waste problem (Zhang et al., 2019). For instance, recent research hotspots are mainly addressing the recycling and post-treatment of e-waste (Van Yken et al., 2021), environmental impacts (Kumar et al., 2017), health hazards (Li and Achal, 2020) and relevant policies that regulate e-waste domain (Borthakur, 2020). Yet, there is no single attempt to investigate key indicators of the economy's well-being to the generation of e-waste, although there are traces that indicate potential causality (Borthakur and Govind, 2017; Kusch and Hills, 2017; Lei et al., 2021). This is important to address, given the dynamic, dominantly urbanized and virtual societies we have at present. Based on the Han et al. (2021) argument, economies with high(er) gross domestic product (GDP) are experiencing higher internet penetration, consumption of electronic products, and it is to expect higher quantities of e-waste. On the other hand, Popli et al. (2021) found that higher literacy leads to higher economic activity, consumption of electronic products and, consequently, it is to expect a higher generation of e-waste. Next, it is a fact that developing and developed countries possess different e-waste regulatory frameworks (a great portion of observed countries does not have a policy at all) (Zhang et al., 2019) - yet, only a small number of countries were subject of investigation (e.g. China, India, European Union, etc.).

Considering the given complexities of the e-waste domain, in our archival study, we investigate, on a global level, if country progress indicators (GDP, literacy rate, internet penetration, urban population), impact the generation of e-waste, to what extent and in what direction. Additionally, we observe if there are major differences between e-waste generation in countries with and without e-waste regulatory framework and between developing and developed economies.

By focusing on data from 172 countries, we found pieces of evidence that primarily support some of the moderating propositions. Notably, the results indicate that GDP, literacy rate, internet penetration and urban population do not directly influence the e-waste generation and greatly extend the understanding of the nature of relations between key development indicators and e-waste generation. Next, higher internet penetration in developing countries leads to higher e-waste, while higher literacy rates in developed countries lead to less e-waste. When it comes to e-waste policy, a higher urban population without a regulatory legal framework leads reportedly to higher e-waste. On a similar note, if there is a legal framework imposed with higher internet penetration, a stronger generation of e-waste is to follow. These findings demystify the diverse situation when it comes to differences in the development of certain countries and the implications of e-waste policies in practice. We now turn to present a theoretical concept, based on which we propose a set of respective hypotheses. Then, we provide an overview of our methodological and statistical 
approach, together with the major results. In closing, we discuss relevant theoretical and managerial implications and propose several distinct research prospects.

\section{Literature review and background \\ Gross domestic product per capita}

GDP is the monetary value of all goods and services produced within a country's geographic boundaries in a given accounting year. The GDP per capita (GDPPC) of a country is derived by dividing its GDP by its entire population. The GDP was first proposed by William Petty, and it was further expanded by Charles Davenant in 1695 (The Economist, 2013). This concept was further improved to measure the economic health of a country in 1944. Later on, it was adopted throughout the world as the measurement tool for the health of an economy (Coyle, 2014).

Around the world, the top 25 economies are measured based on their GDP (Silver, 2020). For developing as well as the developed countries, the internet is widely used communication technology. Internet penetration has been associated with the GDPPC growth rate for developing countries (Geovanny and Suarez, 2008; Kurniawan et al., 2015). It is also observed that not only the GDPPC has a positive influence on internet penetration, rather the internet penetration also boosts the GDP of a country (Asongu and Odhiambo, 2020). Internet penetration boots exports (Ding et al., 2020), increases e-commerce activities (Gerachenko et al., 2020) and raises employment opportunities (Zhu et al., 2018), thereby increasing the GDP of a country. Around the world, GDPPC and internet penetration along with e-waste and urban population are considered to be the indicators of the growth of an economy (Soo and Doolan, 2014; Sverko Grdic et al., 2020). Therefore, many researchers correlate the growth in the GDP and GDPPC with urbanization. It may be possible that the growth in GDPPC does not reflect in the urbanization, and therefore, it is weekly correlated with the growth in the urban population (Guo et al., 2017). In the latest development index, it is found that the internet penetration, e-waste and urban population contribute to the calculation of the economic growth of a country (Dong et al., 2021; Soo and Doolan, 2014). Some studies have found that the increase in GDP is linked with the increase in the use of the internet (Han et al., 2021; Leoveanu-Soare et al., 2020; Raza and Shah, 2020). The countries with higher GDP have observed a higher rate of internet penetration for their urban population as compared to their rural population (Billon et al., 2009; Coyle, 2014; Geovanny and Suarez, 2008; Wentrup et al., 2016). Therefore, to know the influence of GDP on internet penetration, e-waste and urban population, the following hypotheses were formulated:

H1. GDPPC has a significant positive influence on internet penetration (H1a), e-waste (H1b) and urban population (H1c).

\section{Literacy rate}

There is a lack of any established acceptable and equally applicable definition for the concept of literacy (Keefe and Copeland, 2011). However, we are considering the definition of literacy as per the data source of the current study and other previous studies, i.e. the ability of the population of a region to read and write (Edwards and Potts, 2008; Tomaselli and Mboti, 2013; UNESCO Institute of Statistics, 2021). The level of literacy in a country defines its prosperity and the use of science and technology (Campbell, 1990). A higher literate country will have a higher internet penetration (Vincent, 2016). It is observed that the internet penetration depends upon the economic parameters like literacy rate and urbanization (Kurniawan et al., 2015; Vincent, 2016), but it is also observed that a higher literacy rate calls for higher usage of the internet, thereby increasing the internet penetration. A higher literacy rate is associated with the higher usage of gadgets and gizmos, which in a way leads to higher e-waste production (Popli et al., 2021). Higher economic activities are associated with higher e-waste production (Petridis et al., 2017). A higher literacy rate paves the road to higher usage of

\section{Country development indicators and \\ e-waste}

1603 
IJQRM

39,7

1604

mobile gadgets (Zia, 2020a), which is one of the biggest contributors to e-waste (Galang and Ballesteros, 2018). The unavailability of a proper system for the disposal of e-waste, an increase in the urban population and internet penetration led to the contamination of the environment with e-waste (Jayaraman et al., 2019). An increase in literacy rate and urban population arouse the need for proper e-waste disposal and management policies (Zazzau, 2006). The literate population demands the internet and the young population is becoming dependent on it (Zia, 2020b). This further increases internet penetration and thereby enhances e-waste production (Zazzau, 2006). Therefore, to test the influence of literacy rate on internet penetration and e-waste and urban population, the following hypotheses were proposed.

H2. Literacy rate has a significant positive influence on internet penetration $(\mathrm{H} 2 \mathrm{a})$ and ewaste $(\mathrm{H} 2 \mathrm{~b})$ and urban population (H2c).

\section{Internet penetration and its role as mediator}

The concept of internet penetration talks about the percentage of the population having access to the internet technology (Ferro et al., 2010; Kalia et al., 2017). The economic development of any country is associated with the growth in GDPPC (Beckmann and Czudaj, 2017; Kusch and Hills, 2017; Silver, 2020). It is seen that the growth in GDPPC is associated with the growth in urbanization, which leads to a higher e-waste production (Kusch and Hills, 2017). The internet penetration leads to the higher usage of technical gadgets and mobile phones (Kalia, 2019), which is associated with the higher levels of e-waste production (Petridis et al., 2017). It is seen that the economies have grown faster after the advent of the internet, and the growth of the urban population also surged resulting in a higher level of e-waste production (Zhang and Meng, 2019; Zhu et al., 2018). Therefore, to test the role of internet penetration, the following hypotheses were formed:

H3. Internet penetration has a significant positive influence on e-waste.

H4. In the presence of Internet penetration, GDPPC (H4a), literacy rate (H4b) and urban population $(\mathrm{H} 4 \mathrm{c})$ have a significant positive influence on e-waste.

\section{Urban population and its role as mediator}

The human settlement, which is characterized by the high density of population in an area that has the excess to the necessities of life, is considered an urban population (Baten, 2003). In any country, the maximum density of internet users is found to be in urban centers (Kayaoglu and Naval, 2017). The usage of the internet is high in the urban population as compared to the rural population (Petrauskiene and Zilinskas, 2015). Generally, it is observed that a higher rate of urbanization is associated with a higher GDPPC growth rate (Benali, 2021; Cheng et al., 2019; Lei et al., 2021; Liang, 2013). The urban consumption of smartphones and smart gadgets is very high, and their usage depends upon internet penetration, which gives rise to high production of e-waste (Asongu, 2018). Therefore, to test the role of the urban population, the following hypotheses were formed.

H5. The urban population has a significant positive influence on internet penetration.

H6. The urban population has a significant positive influence on e-waste.

H7. In the presence of the urban population, GDPPC (H7a) and literacy rate (H7b) have a significant positive influence on e-waste.

\section{Country development levels and e-waste policy as moderators}

The development of any country is directly or indirectly associated with the use of electronic gadgets (Generowicz and Iwanejko, 2017; Little and Lucier, 2017; Wu et al., 2012). This usage increases with the increase of economic development, thereby producing a higher level of 
e-waste. The developed countries have a higher potential for maintaining an e-waste system (Li et al., 2015). The developing countries do not have well-defined e-waste policies and therefore contribute more to e-waste (Mejame et al., 2020). Countries should strive to develop some e-waste policies to manage e-waste production for the benefit of the environment (Cole et al., 2018), to recycle (Garg, 2020) and to develop alternative technologies (Mejame et al., 2020; Peagam et al., 2013). The developed and developing countries differently prioritize the ewaste management system and policies (Kaminsky, 2016; Liddle, 2013). The e-waste policies are not the determinant factor of the development of any country. Many developed countries do not have e-waste policies, whereas some developing countries have e-waste policies (Kaminsky, 2016; Liddle, 2013; Pariatamby and Victor, 2013). Therefore, to test this relationship, the following hypotheses were framed.

H8. Significant differences exist between the underdeveloped and developed countries for the links in the model.

H9. Significant differences exist between the countries without and with an effective ewaste policy for the links in the model.

\section{Methodology}

Research context

The current research considered an international perspective to explore the effect of GDPPC, literacy rate, internet penetration and urban population on e-waste generation. Further, we checked the mediating role of internet penetration, and urban population, and the moderating effect of country development status and e-waste legislation within the proposed model. Since e-waste data were available for 172 countries only, therefore remaining information was compiled against the same and processed for further analysis.

\section{Data collection}

For the study, we collected secondary data from various reliable resources. The data relating to GDPPC, literacy rate, internet penetration and the urban population were collected from the World Bank (2021). Information regarding country development status was compiled from the United Nations (2020). For e-waste statistics, i.e. e-waste generated and national e-waste policy in place, we relied on the report published by the Global E-waste Statistics Partnership (Forti et al., 2020). As depicted in the descriptive analysis (Table 1), the sample comprised a higher percentage of developing countries $(77.9 \%)$ than developed countries $(22.1 \%)$. A little more than half the number of countries $(54.1 \%)$ had no formal e-waste policy, whereas the remaining $(45.9 \%$ ) had it. The sample comprised of countries from Asia (26.7\%), Africa (25.6\%), Europe (22.7\%), Americas (19.2\%) and Oceania (5.8\%). We followed $N$ :q rule to determine the sample size (where $N=$ number of cases and $q=$ the number of model parameters that require statistical estimates). A recommended sample-size to-parameter ratio is 20:1 (Jackson, 2003). Since we had a model based on five continuous variables, the recommended minimum sample size was 100 , our sample was quite larger than the recommended sample size.

\section{Data analysis and findings \\ Structural model}

For the path analysis of the proposed model (Figure 1), we used Stata 16 software. We observed that GDPPC has a positive influence on internet penetration $(\beta=0.001, p<0.01)$ and urban population $(\beta=0.001, p<0.01)$. Similarly, we noticed that literacy rate has a significant and positive influence on internet penetration $(\beta=0.688, p<0.01)$ and urban 


\section{IJQRM \\ 39,7}

\begin{tabular}{lrr}
\hline Characteristics & $N$ & $\%$ \\
\hline Country development status & & \\
Developing & 134 & 77.9 \\
Developed & 38 & 22.1 \\
E-waste policy & & \\
No & 93 & 54.1 \\
Yes & 79 & 45.9 \\
Region & & \\
Americas & 33 & 19.2 \\
Asia & 46 & 26.7 \\
Africa & 44 & 25.6 \\
Europe & 39 & 5.8 \\
Oceania & 10 & \\
Source(s): Authors' calculations & &
\end{tabular}

Figure 1.

Structural model \begin{tabular}{l}
1606 \\
\hline \\
Table 1. \\
Characteristics of the \\
sample
\end{tabular}

\begin{tabular}{l}
1606 \\
\hline \\
Table 1. \\
Characteristics of the \\
sample
\end{tabular}

E-waste policy

Asia

Africa

Source(s): Authors' calculations
77.9

54.1

45.9

19.2

26.7

25.6

5.8

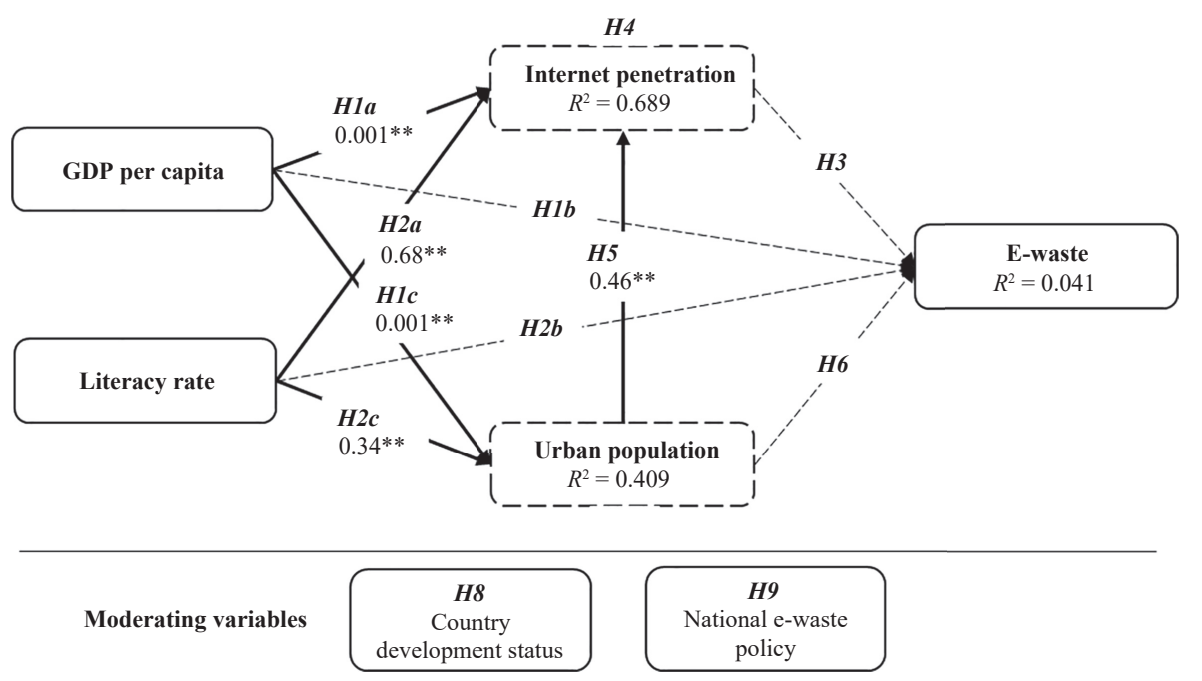

Note(s): Mediators in dotted boxes

population $(\beta=0.342, p<0.01)$. Additionally, it was found that the urban population positively impacts internet penetration $(\beta=0.469, p<0.01)$. Surprisingly, no significant influence of GDPPC, literacy rate, internet penetration and the urban population was found on e-waste generation (Table 2). On examining the equation-level goodness of fit, we noticed that the $R^{2}$ value for internet penetration is 0.689 , which means that a $68.9 \%$ change in internet penetration is explained by GDPPC, literacy rate and urban population. Whereas, $40.9 \%$ variance in urban population is determined by GDPPC and literacy rate. However, only $4.1 \%$ of the variance in e-waste generation is explained by all the other factors in the proposed model (Table 3).

\section{Mediation analysis}

Further, we examined the mediating effect of internet penetration, and urban population between GDPPC, literacy rate and e-waste generation (Table 4). We noticed no mediation 


\begin{tabular}{lccclll}
\hline Effects & Coef & OIM std. err. & $z$ & $p>z$ & Hypotheses & Result \\
\hline internet $\leftarrow$ gdp & 0.001 & 0.000 & 7.960 & $0.000^{* * *}$ & H1a & Accepted \\
ewaste $\leftarrow$ gdp & 0.006 & 0.004 & 1.370 & 0.170 & H1b & Rejected \\
urban_p $\leftarrow$ gdp & 0.001 & 0.000 & 6.910 & $0.000^{* *}$ & H1c & Accepted \\
internet $\leftarrow$ literacy & 0.688 & 0.076 & 9.020 & $0.000^{* *}$ & H2a & Accepted \\
ewaste $\leftarrow$ literacy & 2.728 & 4.352 & 0.630 & 0.531 & H2b & Rejected \\
urban_p $\leftarrow$ literacy & 0.342 & 0.076 & 4.490 & $0.000^{* *}$ & H2c & Accepted \\
ewaste $\leftarrow$ Internet & 8.314 & 4.876 & 1.710 & 0.088 & H3 & Rejected \\
internet $\leftarrow$ urban_p & 0.469 & 0.067 & 6.960 & $0.000^{* *}$ & H5 & Accepted \\
ewaste $\leftarrow$ urban_p & 3.395 & 4.347 & 0.780 & 0.435 & H6 & Rejected
\end{tabular}

Country development indicators and e-waste 1607

Note(s): **Significant at $1 \%$, *significant at $5 \%$

Source(s): Authors' calculations

Table 2.

Results of the structural model

\begin{tabular}{lrrrrrr}
\hline & & Variance & & & \\
depvars & \multicolumn{1}{c}{ Fitted } & Predicted & Residual & $R$-squared & $\mathrm{mc}$ & $\mathrm{mc}^{2}$ \\
\hline internet & 780.004 & 537.335 & 242.670 & 0.689 & 0.830 & 0.689 \\
urban_p & 525.009 & 214.585 & 310.424 & 0.409 & 0.639 & 0.409 \\
ewaste & $1,034,818.000$ & $42,613.330$ & $992,204.400$ & 0.041 & 0.203 & 0.041
\end{tabular}

Note(s): Overall $=0.623, \mathrm{mc}=$ correlation between depvar and its prediction

Table 3.

$\mathrm{mc}^{2}=\mathrm{mc}^{2}$ is the Bentler-Raykov squared multiple correlation coefficient

Source: Authors' calculations

Equation-level goodness of fit

\begin{tabular}{lcccccc}
\hline Effects & Coef & Std. err & $z$ & $p>z$ & Hypotheses & Result \\
\hline ewaste $\leftarrow$ Internet $\leftarrow$ gdp & 2.886 & 1.799 & 1.604 & 0.109 & H4a & Rejected \\
ewaste $\leftarrow$ Internet $\leftarrow$ literacy & 4.381 & 2.637 & 1.662 & 0.097 & H4b & Rejected \\
ewaste $\leftarrow$ Internet $\leftarrow$ urban_p & 3.901 & 2.355 & 1.656 & 0.098 & H4c & Rejected \\
ewaste $\leftarrow$ urban_p $\leftarrow$ gdp & -0.257 & 2.478 & -0.1 & 0.917 & H7a & Rejected \\
ewaste $\leftarrow$ urban_p $\leftarrow$ literacy & -0.173 & 1.672 & -0.1 & 0.917 & H7b & Rejected
\end{tabular}

Note(s): Baron and Kenny approach to testing mediation using medsem package in Stata 16

Source(s): Authors' calculations

Table 4.

Mediation analysis

effect of internet penetration on the relationship between GDPPC, literacy rate, urban population and e-waste generation. Similarly, no mediating effect of urban population was found on the relationships between GDPPC, literacy rate and e-waste generation. Hence, all the hypotheses under mediation analysis were rejected.

\section{Multigroup analysis}

In the next stage, we conducted a multigroup analysis based on country development status and the presence or absence of e-waste policies in the countries. For country development status (Table 5), we noticed that unlikely in the case of developed countries, both GDPPC $(\beta=0.001, p<0.01)$ and literacy rate $(\beta=0.455, p<0.01)$ can positively increase internet penetration in developing countries. Further, it was found that literacy rate $\beta=0.284$, $p<0.01)$ can lead to an increase in the urban population in the case of developing countries. Most importantly, we found that an increase in internet penetration is leading to an increase in e-waste generation $(\beta=9.588, p<0.01)$ in the case of developing countries. In the same context, an important finding was a decrease in e-waste generation with the increase in literacy rate in the case of developed countries $(\beta=-355.644, p<0.01)$. 


\section{IJQRM \\ 39,7}

Table 5.

1608

\begin{tabular}{llrrrr}
\hline Effect & Dev. status & \multicolumn{1}{c}{ Coef. } & OIM std. err. & $z$ & $p>z$ \\
\hline internet $\leftarrow$ urban_p & Developing & 0.424 & 0.079 & 5.400 & $0.000^{* *}$ \\
& Developed & 0.464 & 0.092 & 5.050 & $0.000^{* *}$ \\
internet $\leftarrow$ gdp & Developing & 0.001 & 0.000 & 4.310 & $0.000^{* *}$ \\
& Developed & 0.000 & 0.000 & 1.660 & 0.096 \\
internet $\leftarrow$ literacy & Developing & 0.455 & 0.080 & 5.670 & $0.000^{* *}$ \\
& Developed & 0.670 & 0.466 & 1.440 & 0.150 \\
urban_p $\leftarrow$ gdp & Developing & 0.001 & 0.000 & 5.600 & $0.000^{* *}$ \\
& Developed & 0.000 & 0.000 & 4.290 & $0.000^{* *}$ \\
urban_p $\leftarrow$ literacy & Developing & 0.284 & 0.085 & 3.360 & $0.001^{* *}$ \\
& Developed & -0.665 & 0.815 & -0.820 & 0.414 \\
ewaste $\leftarrow$ Internet & Developing & 9.588 & 4.844 & 1.980 & $0.048^{*}$ \\
& Developed & 24.329 & 18.129 & 1.340 & 0.180 \\
ewaste $\leftarrow$ urban_p & Developing & -0.968 & 4.859 & -0.200 & 0.842 \\
& Developed & -10.113 & 13.272 & -0.760 & 0.446 \\
ewaste $\leftarrow$ gdp & Developing & -0.011 & 0.009 & -1.180 & 0.237 \\
& Developed & 0.004 & 0.007 & 0.540 & 0.587 \\
ewaste $\leftarrow$ literacy & Developing & 0.076 & 5.003 & 0.020 & 0.988 \\
& Developed & -355.644 & 53.434 & -6.660 & $0.000^{* *}$ \\
Note(s): $* *$ Significant at $1 \%$, *significant at $5 \%$ & & & & \\
Source: Authors' calculations & & & & \\
\hline
\end{tabular}

In the case of absence or presence of e-waste policy in the countries (Table 6), we found that increase in literacy rate is leading to a higher urban population $(\beta=0.579, p<0.01)$ in the countries with e-waste policy. An interesting finding was an increase in e-waste generation $(\beta=33.233, p<0.01)$ due to an increase in internet penetration in countries with e-waste policies. As expected, a significant increase in e-waste $(\beta=3.730, p<0.05)$ was noticed with the increase in the urban population in the case of countries without e-waste policy. based on development status of countries

Source: Authors' calculations

\begin{tabular}{llcccc}
\hline Effect & Policy & Coef. & OIM std. err. & $z$ & $p>z$ \\
\hline internet $\leftarrow$ urban_p & No & 0.409 & 0.094 & 4.350 & $0.000^{* *}$ \\
internet $\leftarrow$ gdp & Yes & 0.324 & 0.084 & 3.870 & $0.000^{* *}$ \\
& No & 0.001 & 0.000 & 4.860 & $0.000^{* *}$ \\
internet $\leftarrow$ literacy & Yes & 0.000 & 0.000 & 3.400 & $0.001^{* *}$ \\
& No & 0.352 & 0.090 & 3.900 & $0.000^{* *}$ \\
urban_p $\leftarrow$ gdp & Yes & 0.806 & 0.117 & 6.900 & $0.000^{* *}$ \\
& No & 0.001 & 0.000 & 4.790 & $0.000^{* *}$ \\
urban_p $\leftarrow$ literacy & Yes & 0.000 & 0.000 & 4.600 & $0.000^{* *}$ \\
& No & 0.170 & 0.098 & 1.740 & 0.082 \\
ewaste $\leftarrow$ Internet & Yes & 0.579 & 0.143 & 4.060 & $0.000^{* *}$ \\
& No & 0.975 & 1.908 & 0.510 & 0.610 \\
ewaste $\leftarrow$ urban_p & Yes & 33.233 & 14.196 & 2.340 & $0.019^{*}$ \\
& No & 3.730 & 1.896 & 1.970 & $0.049^{*}$ \\
ewaste $\leftarrow$ gdp & Yes & -9.435 & 11.541 & -0.820 & 0.414 \\
& No & -0.007 & 0.004 & -1.560 & 0.120 \\
ewaste $\leftarrow$ literacy & Yes & -0.003 & 0.008 & -0.340 & 0.732 \\
& No & 1.627 & 1.792 & 0.910 & 0.364 \\
& Yes & -31.149 & 18.662 & -1.670 & 0.095
\end{tabular}

Multigroup analysis based on e-waste policies in countries

Note(s): **Significant at $1 \%$, *significant at $5 \%$

Source(s): Authors' calculations 


\section{Discussion}

This article examined the relationships between GDPPC and literacy on e-waste generation, with internet penetration and urban population as mediators and country development status and e-waste legislation as moderators in the proposed model. The current study divulges some interesting findings to the existing research on e-waste.

Established on the previous literature, we hypothesized that GDPPC has a significant positive influence on internet penetration (H1a), e-waste (H1b) and urban population (H1c). We observed that GDPPC has a positive influence on internet penetration and urban population. These findings are concurrent to the previous studies that have positively correlated GDPPC with internet penetration (Asongu and Odhiambo, 2020) and urban population (Guo et al., 2017). Further, we hypothesized that literacy rate has a significant positive influence on internet penetration (H2a) and e-waste ( $\mathrm{H} 2 \mathrm{~b})$ and urban population (H2c). We noticed that the literacy rate has a significant and positive influence on internet penetration and the urban population. These findings are in tune with the past studies that positively link literacy with high internet penetration (Vincent, 2016) and urbanization (Kurniawan et al., 2015). However, the assumption of literacy as a precursor of e-waste contradicts the previous studies (Galang and Ballesteros, 2018). Additionally, we checked if the urban population (H5) has a significant positive influence on internet penetration, which turned out to be true as supported by previous literature (Kayaoglu and Naval, 2017). We checked any direct influence of internet penetration (H3) and urban population (H6) on e-waste generation, but we found no significant effects. These findings are contradictory to the assumptions that internet penetration (Petridis et al.,2017) or urbanization (Asongu, 2018) will lead to the higher usage of technical gadgets and mobiles phones, leading to higher levels of e-waste production. Taking the analysis further, we checked the mediating roles of internet penetration (H4) and urban population (H7) within the model and did not notice any significant influence.

An important contribution of this research is determining the moderating roles of country development status (H8) and absence or presence of e-waste policy in the country (H9). Based on country development status, we observed significant differences in the structural model at internet penetration-GDPPC (H1a), internet penetration-literacy rate (H2a), urban population-literacy rate (H2c), e-waste generation-internet penetration (H3) and e-waste generation-literacy rate $(\mathrm{H} 2 \mathrm{~b})$ links. The most interesting part of these results was the findings related to e-waste generation, where the e-waste generation-internet penetration (H3) link was positively significant for developing countries and the e-waste generation-literacy rate (H2b) link was negatively significant for the developed countries, i.e. with more literacy in developed countries the amount of e-waste goes down. These findings negate the assumptions of the previous authors who hinted a direct or indirect link between the use of electronic gadgets with the increase of economic development in a country and thereby producing a higher level of e-waste (Generowicz and Iwanejko, 2017; Little and Lucier, 2017; Wu et al., 2012). While checking the moderating effect of e-waste policy, significant differences on the structural model were observed at the urban population-literacy rate (H2c), e-waste generation-internet penetration (H3) and e-waste generation-urban population (H6) links. Surprisingly, we found that internet penetration is significantly and positively contributing to e-waste generation in the countries with e-waste policies. Probably, it is because many developing countries have implemented e-waste legislation to curb the evil of e-waste (Kaminsky, 2016; Liddle, 2013; Pariatamby and Victor, 2013) (Table 7). The second observation was quite pertinent as it indicated an increase in e-waste due to an increase in the urban population in the countries without e-waste policy. Together, these differences provide support for $\mathrm{H} 8$ and $\mathrm{H} 9$.

\section{Country development indicators and \\ e-waste}

1609 
IJQRM

39,7

1610

\section{Theoretical contributions and implications}

Country development indicators are not the real cause of e-waste

Firstly, this research confirmed that GDPPC, literacy rate, internet penetration and urban population do not directly influence e-waste. Overall, these factors define only a $4.1 \%$ variance in e-waste generation, giving room for other factors to be explored in the future (e.g. shifting consumer behavior and lifestyle, novel trends in technology, etc.). On the brighter side, we noticed that GDPPC, literacy rate and urban population define internet penetration quite well $(68.9 \%)$.

\section{Developing at the cost of e-waste}

Secondly, the study confirmed that an increase in internet penetration in developing countries is leading to e-waste generation. One of the possible reasons for the same could be that developed countries have already reached saturation in terms of internet penetration, which is not the case for developing countries. The middle class in developing countries is getting more populous with the increasing purchasing power, which supposedly reflects onto increasing consumption of electronic devices (Islam and Huda, 2019). On the other hand, the upslope economic activity in developing nations requires companies to be on technological edge to stay on the world market - which in turn puts additional pressure on the evergrowing consumption of various electronic devices. Yet, the question remains what are the ecological and human costs we can bear to support our societal economic well-being?

\section{Literacy can induce ethical consumerism}

Thirdly, the study determined that increase in literacy rate in developed countries is leading to a decrease in e-waste. It indicates a shift from consumerism to environmentalism or at least conscious or ethical consumerism in developed countries due to knowledge and literacy. Next to that, it implies the human capital that is oriented to a long-term perspective, whereby ad $h o c$-based convenience that electronic devices provide, is not the prime focus. As a side remark, it emerges that domains of ethical consumerism and the concept of environmentalism must be better addressed in societies across both developed and developing countries. As the ultimate consequences are felt with no reference to developed, developing or so-called "thirdworld" countries.

\section{From legislation to a way of life}

Fourthly, the increase in e-waste due to internet penetration in countries with e-waste policy indicates that merely implementing legislation is not enough until it is not adopted at an individual level, i.e. citizens should not follow the policy out of fear, but through the awareness of their actions impacting the environment. Countries must ensure a strategic approach in terms of promoting certain lifestyles (e.g. health-focused behavior), consumption patterns (e.g. leaning toward ethical consumption), long-term sustainable framework (e.g. promotion of sustainability concepts and their terminal importance) - on all levels to combat

Table 7.

Crosstab of country development status and e-waste policy

\begin{tabular}{lccr}
\hline & & & \\
Country development status & No & Yes & Total \\
\hline Developing & 91 & 43 & 134 \\
Developed & 2 & 36 & 38 \\
Total & 93 & 79 & 172 \\
Source(s): Authors' calculations & & & \\
\hline
\end{tabular}


the growing e-waste problem. An institutional framework fully incepted in the daily life of society should cater to all these activities (e.g. schools, agencies, local authorities, national ministries, etc.). In closing, given the complexity of the e-waste issue, it requires a convoluted multi-layered approach in its permanent-solving.

The global urge for a unified approach in managing e-waste

The massive gaps are present in terms of how different countries approach e-waste. There is a certain level of harmonization in the European Union, but other than that - each country approaches the issue in its manner. Next, more than half of the accounted countries do not have even an official legal framework to tackle the issue - basically not recognizing e-waste as a particular problem at all. United Nations indeed has directives to curb the problem of ewaste, yet, only with as a recommendation (United Nations, 2017). To handle the issues of toxic substances spilling over to the ecosystems and affecting human wellbeing, we must stand together. Unfortunately, the current practices where most e-waste from developed countries is shipped to uncontrolled landfills in Africa and Asia is not acceptable, ethical and long-term sustainable (Vidal, 2013).

\section{Conclusion}

The study investigated the impact of country development indicators, i.e. GDPPC and literacy rate, on e-waste on a global level, with internet penetration and urban population as mediators. Further, we examined the role of country development status and e-waste policy as mediators. For analysis, we collected data for 172 countries from the United Nations, World Bank and Global E-waste Statistics Partnership. The results of path analysis of the proposed research model revealed that GDPPC, literacy rate, internet penetration and urban population do not directly influence the generation of e-waste. However, higher internet penetration in developing countries leads to higher e-waste, while higher literacy rates in developed countries suppress e-waste generation. When it comes to e-waste policy, a higher urban population without a regulatory legal framework boosts higher e-waste. We observed that higher internet penetration leads to higher e-waste in the presence of e-waste policy as well. This is the first study to include economic well-being indicators in elaborating e-waste generation, on a global scale.

\section{Limitations and future directions}

Regardless of the substantial findings of the current study, certain limitations exist. First, data were collected for only 172 countries. Future researchers can cover all the countries in the world. Second, GDPPC, literacy rate, internet penetration and urban population define only $4.1 \%$ variance in e-waste generation, giving room for other factors like teledensity, smartphone penetration, etc. (Kalia et al., 2021) to be explored in the future. Third, we classified the countries based on development status as developed or developing only to maintain a decent sample size for multigroup analysis. Therefore, more precise classification can be used to have more decisive findings. Fourth, it would be interesting to see the continent-wise perspective on e-waste. Fifth, researchers have classified 54 electrical and electronic equipment (EEE) into six broad categories of e-waste, i.e. temperature exchange equipment, lamps, screens and monitors, small equipment, large equipment, small information technology and telecommunication equipment. Therefore, future researchers can explore the problem of e-waste concerning specific categories as previous studies have indicated that the life of complex and multifunction devices is short (Bhargava et al., 2014). However, if the lifetime and failure time of an electronic gadget is predicted (Shivani and Bhargva, 2018), then techniques can be employed to reduce e-waste (Bhargava and Sharma, 2021). 
IJQRM

39,7

\section{References}

Andersson, M., Ljunggren Söderman, M. and Sandén, B. (2019), "Adoption of systemic and sociotechnical perspectives in waste management, WEEE and ELV research", Sustainability, Vol. 11 No. 6, p. 1677.

Asongu, S.A. (2018), "Conditional determinants of mobile phones penetration and mobile banking in Sub-Saharan Africa", Journal of the Knowledge Economy, Vol. 9 No. 1, pp. 81-135.

Asongu, S.A. and Odhiambo, N.M. (2020), "Foreign direct investment, information technology and economic growth dynamics in Sub-Saharan Africa”, Telecommunications Policy, Vol. 44 No. 1, p. 101838

Baten, J. (2003), "Creating firms for a new century: determinants of firm creation around 1900", European Review of Economic History, Vol. 7 No. 3, pp. 301-329.

Beckmann, J. and Czudaj, R. (2017), "Capital flows and GDP in emerging economies and the role of global spillovers", Journal of Economic Behavior and Organization, Vol. 142, pp. 140-163.

Benali, N. (2021), "The dynamic links between natural disaster, health spending, and GDP growth: a case study for lower middle-income countries", Journal of the Knowledge Economy, ahead-ofprint, doi: 10.1007/s13132-021-00793-y.

Bhargava, C., Banga, V.K. and Singh, Y. (2014), "Failure prediction and health prognostics of electronic components: a review", 2014 Recent Advances in Engineering and Computational Sciences, RAECS 2014, IEEE Conference, Chandigarh, doi: 10.1109/RAECS.2014.6799572.

Bhargava, C. and Sharma, P.K. (2021), "Statistical and intelligent reliability analysis of multi-layer ceramic capacitor for ground mobile applications using Taguchi's approach", International Journal of Quality and Reliability Management, ahead-of-print, doi: 10.1108/IJQRM-09-2020-0316.

Billon, M., Marco, R. and Lera-Lopez, F. (2009), "Disparities in ICT adoption: a multidimensional approach to study the cross-country digital divide", Telecommunications Policy, Vol. 33 Nos 10-11, pp. 596-610.

Borthakur, A. (2020), "Policy approaches on E-waste in the emerging economies: a review of the existing governance with special reference to India and South Africa”, Journal of Cleaner Production, Vol. 252, p. 119885.

Borthakur, A. and Govind, M. (2017), "Emerging trends in consumers' E-waste disposal behaviour and awareness: a worldwide overview with special focus on India", Resources, Conservation and Recycling, Vol. 117, pp. 102-113.

Campbell, B. (1990), "What is literacy? Acquiring and using literacy skills", Australasian Public Libraries and Information Services, Vol. 3 No. 3, pp. 149-152.

Cheng, R., Chen, W., Wu, S. and Lin, J. (2019), "Spatiotemporal variation characteristics of ecosystems and their driving forces in the Min Delta urban agglomeration", International Review for Spatial Planning and Sustainable Development, Vol. 7 No. 1, pp. 177-194.

Cole, C., Gnanapragasam, A., Singh, J. and Cooper, T. (2018), "Enhancing reuse and resource recovery of electrical and electronic equipment with reverse logistics to meet carbon reduction targets", Procedia CIRP, Copenhagen, Denmark, Vol. 69, pp. 980-985.

Coyle, D. (2014), "Warfare and the invention of GDP", available at: https://www.theglobalist.com/ warfare-and-the-invention-of-gdp/ (accessed 13 August 2021).

Ding, H.C., Wang, G., Zhong, Z., Xu, Q., Wu, Q., Zhong, Y., Zhan, Y. and Li, M. (2020), "Regression analysis on correlation of China's export via cross-border e-commerce", The International Journal of Electrical Engineering and Education, ahead-of-print, doi: 10.1177/0020720920923663.

Dong, F., Li, J., Zhang, X. and Zhu, J. (2021), "Decoupling relationship between haze pollution and economic growth: a new decoupling index", Ecological Indicators, Vol. 129, p. 107859.

Edwards, D. and Potts, A. (2008), "What is literacy? Thirty years of Australian literacy debates (19752005)”, Paedagogica Historica, Vol. 44 Nos 1-2, pp. 123-135. 
Favot, M. and Grassetti, L. (2017), "E-waste collection in Italy: results from an exploratory analysis", Waste Management, Vol. 67, pp. 222-231.

Ferro, E., Dwivedi, Y.K., Gil-Garcia, J.R. and Williams, M.D. (Eds) (2010), in Handbook of Research on Overcoming Digital Divides, IGI Global, Hershey, PA, doi: 10.4018/978-1-60566-699-0.

Forti, V., Baldé, C.P., Kuehr, R. and Bel, G. (2020), “The global E-waste monitor 2020: quantities, flows, and the circular economy potential", available at: https://globalewaste.org/publications/ (accessed 13 April 2021).

Galang, M.G.K. and Ballesteros, F. (2018), "Estimation of waste mobile phones in the Philippines using neural networks", Global Nest Journal, Vol. 20 No. 4, pp. 767-772.

Garg, C.P. (2020), "A robust hybrid decision model to evaluate critical factors of reverse logistics implementation using Grey-DEMATEL framework”, OPSEARCH, Vol. 57 No. 3, pp. 837-873.

Generowicz, A. and Iwanejko, R. (2017), "Environmental risks related to the recovery and recycling processes of waste electrical and electronic equipment (WEEE)", Problemy Ekorozwoju, Vol. 12 No. 2, pp. 181-192.

Geovanny, C. and Suarez, L. (2008), "Factors affecting internet adoption in Latin America", in 2008 Third International Conference on Convergence and Hybrid Information Technology, Vol. 2, IEEE, pp. 947-951.

Gerachenko, I.P., Kuldiaeva, A.A., Dus, J.P., Dyrka, S. and Seitakhmetova, N.L. (2020), "Forecast of development of the global E-commerce market", The Bulletin, Vol. 4 No. 386, pp. 157-164.

Guo, X., Shi, J., Ren, D., Ren, J. and Liu, Q. (2017), “Correlations between air pollutant emission, logistic services, GDP, and urban population growth from vector autoregressive modeling: a case study of Beijing", Natural Hazards, Vol. 87 No. 2, pp. 885-897.

Han, Y., Li, H., Xiao, Y., Li, A. and Zhu, T. (2021), "Influential path of social risk factors toward suicidal behavior-evidence from Chinese sina weibo users 2013-2018", International Journal of Environmental Research and Public Health, Vol. 18 No. 5, pp. 1-14.

Islam, M.T. and Huda, N. (2019), "E-waste in Australia: generation estimation and untapped material recovery and revenue potential”, Journal of Cleaner Production, Vol. 237, p. 117787.

Jackson, D.L. (2003), "Revisiting sample size and number of parameter estimates: some support for the N:q hypothesis", Structural Equation Modeling: A Multidisciplinary Journal, Vol. 10 No. 1, pp. 128-141.

Jayaraman, K., Vejayon, S., Raman, S. and Mostafiz, I. (2019), “The proposed e-waste management model from the conviction of individual laptop disposal practices - an empirical study in Malaysia”, Journal of Cleaner Production, Vol. 208, pp. 688-696.

Kalia, P. (2019), "Web surfers are web spenders: finding the truth of online shopping", International Journal of Management Practice, Vol. 12 No. 3, pp. 376-400.

Kalia, P., Kaur, N. and Singh, T. (2017), "E-commerce in India: evolution and revolution of online retail", in Khosrow-Pour, M. (Ed.), Mobile Commerce: Concepts, Methodologies, Tools, and Applications, IGI Global, Hershey, PA, pp. 736-758.

Kalia, P., Kaushal, R., Singla, M. and Parkash, J. (2021), "Determining the role of service quality, trust, and commitment to customer loyalty for telecom service users: a PLS-SEM approach", The TQM Journal, Vol. 33 No. 7, pp. 377-396.

Kaminsky, J.A. (2016), "Cultured construction: global evidence of the impact of national values on piped-to-premises water infrastructure development”, Environmental Science and Technology, Vol. 50 No. 14, pp. 7723-7731.

Kayaoglu, A. and Naval, J. (2017), "Urbanisation, education and the growth backlog of Africa”, Journal of African Economies, Vol. 26 No. 5, pp. 584-606.

Keefe, E.B. and Copeland, S.R. (2011), "What is literacy? The power of a definition", Research and Practice for Persons with Severe Disabilities, Vol. 36 Nos 3-4, pp. 92-99. 
IJQRM

39,7

1614

Kumar, A., Holuszko, M. and Espinosa, D.C.R. (2017), "E-waste: an overview on generation, collection, legislation and recycling practices", Resources, Conservation and Recycling, Vol. 122, pp. 32-42.

Kurniawan, A., Zakia, I., Wartika, E. and Austin, A.G.G. (2015), "Accelerating internet penetration to rural areas: a government-sponsored internet-kiosks deployment project in Garut Regency, West Java of Indonesia”, in 2015 9th International Conference on Telecommunication Systems Services and Applications (TSSA), pp. 1-6.

Kusch, S. and Hills, C.D. (2017), "The link between e-waste and GDP-new insights from data from the pan-European region", Resources, Vol. 6 No. 2, p. 15.

Lei, W., Jiao, L., Xu, G. and Zhou, Z. (2021), "Urban scaling in rapidly urbanising China”, Urban Studies, ahead-of-print, doi: 10.1177/00420980211017817.

Leoveanu-Soare, B.E., Petre, L.I. and Micu, M.M. (2020), "Social and economic aspects regarding the development of agriculture in Romania", Scientific Papers: Management, Economic Engineering in Agriculture and Rural Development, Vol. 20 No. 2, pp. 281-287.

Li, W. and Achal, V. (2020), "Environmental and health impacts due to e-waste disposal in China - a review", Science of The Total Environment, Vol. 737, p. 139745.

Li, J., Yang, J. and Liu, L. (2015), "Development potential of e-waste recycling industry in China", Waste Management and Research: The Journal for a Sustainable Circular Economy, Vol. 33 No. 6, pp. 533-542.

Liang, B. (2013), "Urban annual water consumption prediction using artificial neural network", Applied Mechanics and Materials, Vols 409-410, pp. 1008-1011.

Liddle, B. (2013), "Population, affluence, and environmental impact across development: evidence from panel cointegration modeling", Environmental Modelling and Software, Vol. 40, pp. 255-266.

Little, P.C. and Lucier, C. (2017), "Global electronic waste, third party certification standards, and resisting the undoing of environmental justice politics", Human Organization, Vol. 76 No. 3, pp. 204-214.

Liu, T., Cao, J., Wu, Y., Weng, Z., Senthil, R.A. and Yu, L. (2021), "Exploring influencing factors of WEEE social recycling behavior: a Chinese perspective", Journal of Cleaner Production, Vol. 312, p. 127829.

Mejame, P.P.M., Jung, D.-Y., Lee, H., Lee, D.S. and Lim, S.-R. (2020), "Effect of technological developments for smartphone lithium battery on metal-derived resource depletion and toxicity potentials", Resources, Conservation and Recycling, Vol. 158, p. 104797.

Pariatamby, A. and Victor, D. (2013), "Policy trends of e-waste management in Asia", Journal of Material Cycles and Waste Management, Vol. 15 No. 4, pp. 411-419.

Patil, R.A. and Ramakrishna, S. (2020), "A comprehensive analysis of e-waste legislation worldwide", Environmental Science and Pollution Research, Vol. 27 No. 13, pp. 14412-14431.

Peagam, R., Mcintyre, K., Basson, L. and France, C. (2013), "Business-to-Business information technology user practices at end of life in the United Kingdom, Germany, and France”, Journal of Industrial Ecology, Vol. 17 No. 2, pp. 224-237.

Petrauskiene, R. and Zilinskas, G. (2015), "The impact of internet penetration on political participation in litvania”, in Kusis, J. (Ed.), Economic Science for Rural Development: Marketing and Sustainable Consumption and New Dimensions in the Development of Society, Latvia University of Agriculture, Jelgava, pp. 122-131.

Petridis, K., Petridis, N., Stiakakis, E. and Dey, P. (2017), "Investigating the factors that affect the time of maximum rejection rate of e-waste using survival analysis", Computers and Industrial Engineering, Vol. 108, pp. 15-26.

Popli, K., Park, C., Han, S.-M. and Kim, S. (2021), "Prediction of solid waste generation rates in urban region of Laos using socio-demographic and economic parameters with a multi linear regression approach", Sustainability, Vol. 13 No. 6, p. 3038. 
Ravindra, K. and Mor, S. (2019), "E-waste generation and management practices in Chandigarh, India and economic evaluation for sustainable recycling", Journal of Cleaner Production, Elsevier, Vol. 221, pp. 286-294.

Raza, M.Y. and Shah, M.T.S. (2020), "Analysis of coal-related energy consumption in Pakistan: an alternative energy resource to fuel economic development", Environment, Development and Sustainability, Vol. 22 No. 7, pp. 6149-6170.

Shittu, O.S., Williams, I.D. and Shaw, P.J. (2021), "Global E-waste management: can WEEE make a difference? A review of e-waste trends, legislation, contemporary issues and future challenges", Waste Management, Pergamon, Vol. 120, pp. 549-563.

Shivani and Bhargva, C. (2018), "DSSBD: an intelligent decision support system for residual life estimation of PN junction diode", Pertanika Journal of Science and Technology, Vol. 26 No. 3, pp. $1241-1252$.

Silver, C. (2020), "Countries by GDP: the top 25 economies in the world", Investopedia, available at: https://www.investopedia.com/insights/worlds-top-economies/ (accessed 13 August 2021).

Soo, V.K. and Doolan, M. (2014), "Recycling mobile phone impact on life cycle assessment", Procedia CIRP, edited by Lien, T., Elsevier Science Bv, Vol. 15, pp. 263-271.

Sverko Grdic, Z., Krstinic Nizic, M. and Rudan, E. (2020), "Circular economy concept in the context of economic development in EU countries", Sustainability, Vol. 12 No. 7, p. 3060.

The Economist (2013), "Petty impressive”, The Economist, available at: https:/www.economist.com/ finance-and-economics/2013/12/21/petty-impressive (accessed 28 September 2021).

The World Bank (2021), "World Bank Open Data: free and open access to global development data", available at: https://data.worldbank.org/ (accessed 13 April 2021).

Tomaselli, K.G. and Mboti, N. (2013), "Doing cultural studies: what is literacy in the age of the post?", International Journal of Cultural Studies, Vol. 16 No. 5, pp. 521-537.

UNESCO Institute of Statistics (2021), “Literacy rate: definition”, available at: http://uis.unesco.org/en/ glossary-term/literacy-rate (accessed 18 October 2021).

United Nations (2017), "United nations system-wide response to tackling E-waste", available at: https://unemg.org/images/emgdocs/ewaste/E-Waste-EMG-FINAL.pdf (accessed 18 October 2021).

United Nations (2020), "World economic situation and prospects", New York, USA, available at: https://www.un.org/development/desa/dpad/wp-content/uploads/sites/45/WESP2020_Annex. pdf (accessed 13 April 2021).

Van Yken, J., Boxall, N.J., Cheng, K.Y., Nikoloski, A.N., Moheimani, N.R. and Kaksonen, A.H. (2021), "E-Waste recycling and resource recovery: a review on technologies, barriers and enablers with a focus on Oceania”, Metals, Vol. 11 No. 8, p. 1313.

Vidal, J. (2013), "Toxic E-waste dumped in poor nations, says united nations", available at: https:// ourworld.unu.edu/en/toxic-e-waste-dumped-in-poor-nations-says-united-nations (accessed 18 October 2021).

Vincent, R.C. (2016), "The internet and sustainable development: communication dissemination and the digital divide", Perspectives on Global Development and Technology, Vol. 15, pp. 605-637.

Wentrup, R., Ström, P. and Nakamura, H.R. (2016), "Digital oases and digital deserts in Sub-Saharan Africa", Journal of Science and Technology Policy Management, Vol. 7 No. 1, pp. 77-100.

Wu, K., Xu, X., Peng, L., Liu, J., Guo, Y. and Huo, X. (2012), “Association between maternal exposure to perfluorooctanoic acid (PFOA) from electronic waste recycling and neonatal health outcomes", Environment International, Vol. 48, pp. 1-8.

Zazzau, V.-E. (2006), "Becoming information literate about information technology and the ethics of toxic waste", Portal: Libraries and the Academy, Vol. 6 No. 1, pp. 99-107.

Zhang, Z. and Meng, X. (2019), "Internet penetration and the environmental Kuznets curve: a crossnational analysis", Sustainability, Vol. 11 No. 5, p. 1358. 
IJQRM 39,7

Zhang, L., Geng, Y., Zhong, Y., Dong, H. and Liu, Z. (2019), “A bibliometric analysis on waste electrical and electronic equipment research", Environmental Science and Pollution Research, Springer Verlag, Vol. 26 No. 21, pp. 21098-21108.

Zhu, Q., Skoric, M.M. and Peng, T.-Q. (2018), “Citizens' use of the internet and public service delivery”, International Journal of Public Administration in the Digital Age, Vol. 5 No. 3, pp. 32-42.

Zia, A. (2020a), "Exploring consumers intent to download mobile application on android vs. iOS platforms in Saudi Arabia”, Pacific Business Review International, Vol. 12 No. 12, pp. 154-182.

Zia, A. (2020b), "Exploring factors influencing online classes due to social distancing in COVID-19 pandemic: a business students perspective", International Journal of Information and Learning Technology, Vol. 37 No. 4, pp. 197-211.

\section{About the authors}

Dr. Prateek Kalia is a post-doctoral researcher at the Department of Corporate Economy, Faculty of Economics and Administration, Masaryk University, Brno, Czech Republic. Earlier, he has worked as Director and Professor at a leading university in North India. He is a specialist in the field of management with a keen interest in e-commerce and consumer behavior. His articles are published in leading international journals, like Computers in Human Behavior, the International Journal of Operations and Production Management, The TQM Journal, the Journal of International Consumer Marketing, etc. He has presented his work at several national and international conferences and received awards and accolades. He holds copyright for a novel concept in mobile commerce. Prateek Kalia can be contacted at: Prateek.Kalia@econ.muni.cz

Dr. Adil Zia is a professor of marketing at Albaha University, College of Business Administration in Saudi Arabia. He has earned his Ph.D. in Marketing from Aligarh Muslim University, India. He has more than 14 years of international teaching and research experience. Service marketing, customer behavior, marketing research, marketing management, retail management and other related topics are among his key interests. He has published research papers in reputable indexed publications, such as Scopus, ABDC, Web of Science and others.

Ing. Dušan Mladenović, Ph.D. is an assistant professor in the Department of Corporate Economy at the Faculty of Economics and Administration, Masaryk University, Brno, Czech Republic. His major research interests are inception of ICT in tourism, digital tourism, word of mouth communication and search engine marketing. He has participated in various research and institutional projects on the university, national and international levels.

For instructions on how to order reprints of this article, please visit our website:

www.emeraldgrouppublishing.com/licensing/reprints.htm

Or contact us for further details: permissions@emeraldinsight.com 